\title{
Study on the Critical Production Calculation Method of the Water-Flooding Reservoir with Gas Cap
}

\author{
Cunliang Chen, Ming Yang, Xue Liu, Fei Shi, Meijia Liu \\ CNOOC China limited Tianjin Branch, Tianjin, China \\ Email: chencl4@cnooc.com.cn
}

How to cite this paper: Chen, C.L., Yang, M., Liu, X., Shi, F. and Liu, M.J. (2019) Paper Title. Open Journal of Yangtze Gas and Oil, 4, 31-42.

https://doi.org/10.4236/ojogas.2019.41003

Received: March 7, 2018

Accepted: January 27, 2019

Published: January 30, 2019

Copyright $\odot 2019$ by authors and Scientific Research Publishing Inc. This work is licensed under the Creative Commons Attribution International License (CC BY 4.0).

http://creativecommons.org/licenses/by/4.0/

\begin{abstract}
The aim of this paper is to solve the problems that the existing method of critical production of gas cap reservoir is only suitable for single-phase flow, and the method of critical production of gas cap reservoir under water-flooding is still blank. In this paper, the relationships between dynamic and static equilibrium, plane radial flow theory, oil-water infiltration method and three-dimensional seepage field decomposition theory, were applied to study a calculation method for critical production of directional wells and horizontal wells. Furthermore, the effects of different factors on critical output were studied, such as horizontal permeability, ratio of horizontal permeability to vertical permeability, length of horizontal section, effective thickness, viscosity of crude oil and water content etc. Results show that the critical production increases with the increment of the horizontal permeability, the ratio of the vertical permeability to the horizontal permeability, the reservoir thickness and the horizontal well length; when the viscosity of crude oil is small, the critical production decreases first and then increases with the increase of water content; when the viscosity of crude oil is high, the critical production increases continuously with the increase of water content. This study could provide theoretical and technical guidance for changing of the working system of oil wells. It can avoid gas channeling and improve the development effect.
\end{abstract}

\section{Keywords}

Water-Flooding, Gas Cap Oilfield, Horizontal Well, Critical Production, Gas Peak Coning, Water Cut

\section{Introduction}

The reservoir with a gas cap is a special reservoir type. After the gas cap reservoir 
was developed, the original balance relationship between oil and gas was broken. Then the gas coning formed near the production well. And then the gas channeling occurred. Although the horizontal wells have an important advantage in delaying the gas cone penetration, a reasonable work system to production is still necessary. At present, scholars have carried out relevant research work. The total pressure drop in the equation of gravity balance was calculated by graphic method, and the critical production was calculated accordingly [1]. Mayer derived the critical production formula based on the continuity equation and Darcy's law [2]. Schols summed up an empirical formula for calculating critical production based on a large number of experimental data [3]. Based on the combination of line source and point source, Wheatly established a new method to calculate the critical production [4]. This method can describe the shape of the conical section. The formula for calculating critical production was established by using the Laplace transform under the condition of constant pressure [5]. Assuming that the free interface is at infinity, Giger established a two-dimensional model of the ridge of water [6]. The model can be used as a reference in the study of gas cone. Using physical simulation, Joshi carried out the study of critical production calculation under the condition of steady flow [7]. Boyun Guo used the conformal transformation to establish the calculation model of the critical production of the horizontal wells [8]. Many researchers have a reference to the research of bottom water reservoir. Fan Zifei used the mirror method and the Muskat formula to calculate the critical production of the horizontal wells [9]. Dou Hong'en modified Chaperon's formula [10]. Based on the Boyun Guo's equation, the perforation location and thickness of vertical well in gas cap bottom water reservoir were studied [11]. Zhou Daiyu carried out different calculation methods and the analysis of uncertainty [12]. Considering the different gas channeling, the researchers used different methods to study the optimal location of horizontal wells [13] [14] [15]. Yao Kai studied the calculation of the critical production under the condition of edge and bottom water [16]. Based on the Boyun Guo's equation, the perforation location of vertical well was studied on different types of reservoirs by Zhou Ke [17]. Chen Yuanqian considered that the output ratio of horizontal well to straight well was the same, and the formula of critical production was established [18]. Tu Bin used the three-dimensional spherical centripetal flow to establish the prediction method for the critical production of thick bottom water reservoirs [19]. Yuan Lin took the principle of ellipsoid flow and the development of the rectangular family method to derive the formula for calculating the critical production of bottom water reservoir [20] [21]. Considering the threshold pressure gradient of heavy oil, a method for calculating critical output was established [22]. These methods are only suitable for single-phase flow. Critical production calculation method of the water flood reservoir with gas cap is still unstudied. So a new method of calculation was proposed in this paper. This method has been used in BZ oil field successfully. The calculation method is simple and practical, and has a certain value. 


\section{Critical Production of Directional Well}

Critical production is the max production when the wells don't have gas breakthrough. The critical condition means that the oil-gas interface stays on the top of well perforation interval steadily, as shown in Figure 1. By the stress analysis of the differential element on GOC, considering the downward force as vertical compressive stress and upward force as stress caused by oil/gas gravity difference, the downward force and the upward force should be equal when the GOC stays stably, as shown in Equation (1).

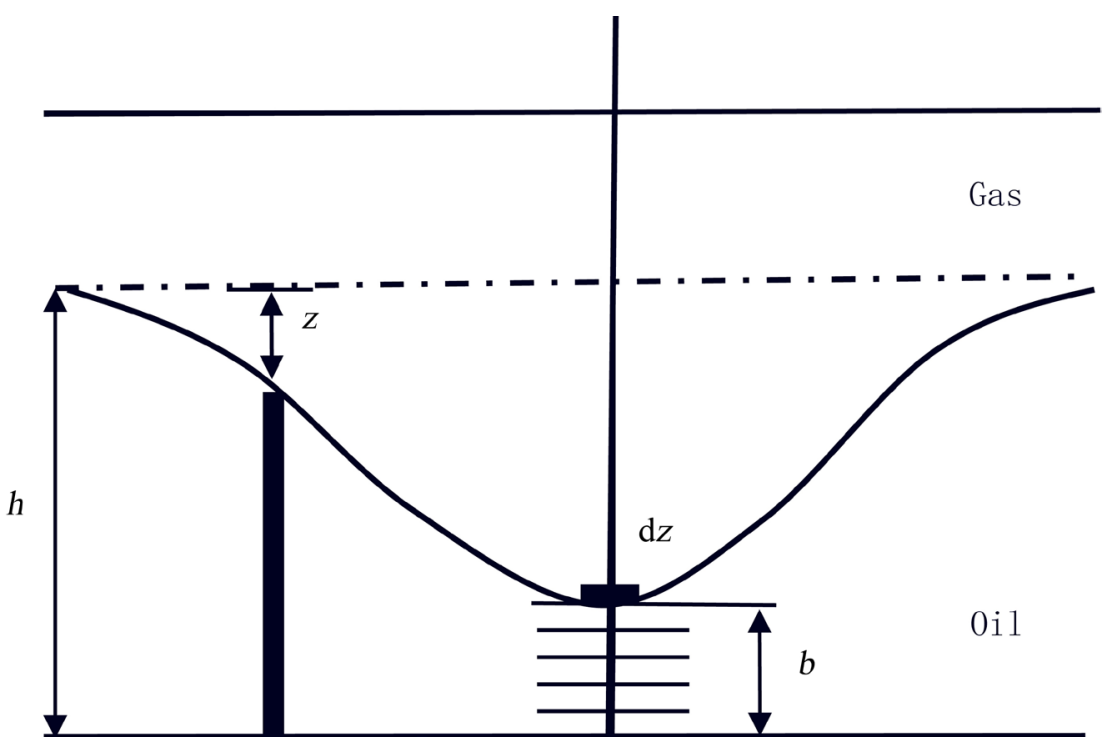

Figure 1. GOC infinitesimal of reservoir with gas cap.

$$
\frac{\mathrm{d} p}{\mathrm{~d} z} \mathrm{~d} z \mathrm{~d} A=-\Delta \rho_{\mathrm{go}} g \mathrm{~d} z \mathrm{~d} A
$$

Then we obtain

$$
\mathrm{d} p=-\Delta \rho_{\mathrm{go}} g \mathrm{~d} z
$$

where $\mathrm{d} p$ is the pressure difference, $\mathrm{d} z$ is the thickness of infinitesimal, $\mathrm{d} A$ is the area of infinitesimal, and $\Delta \rho_{g o}$ is the difference of oil and gas density.

\subsection{Critical Production Calculation before Water Breakthrough}

Before water breakthrough, only oil phase flow into the hole of production well. Based on the theory of radial flow, the migration velocity of fluid is defined by

$$
v=\frac{k}{\mu_{\mathrm{o}}} \frac{\mathrm{d} p}{\mathrm{~d} r}
$$

where $v$ is the migration velocity, $k$ is the absolute permeability, and $\mu_{\mathrm{o}}$ is the oil viscosity.

Production equation is expressed as

$$
q=v A
$$


Cross section area is expressed as

$$
A=2 \pi r(h-z)
$$

Combining Equations (3)-(5), we obtain

$$
q=\frac{k}{\mu_{\mathrm{o}}} \frac{\mathrm{d} p}{\mathrm{~d} r} 2 \pi r(h-z)
$$

From Equations (6) and (2), we can rewrite Equation (6) as

$$
q=\frac{k}{\mu_{\mathrm{o}}} \frac{-\Delta \rho_{\mathrm{go}} g \mathrm{~d} z}{\mathrm{~d} r} 2 \pi r(h-z)
$$

Boundary conditions are considered.

$$
\begin{cases}r=r_{\mathrm{w}} & z=h-b \\ r=r_{\mathrm{e}} & z=0\end{cases}
$$

By integrating Equation (7), we obtain surface critical production.

$$
q_{\mathrm{c}}=\frac{\pi k \Delta \rho_{\mathrm{go}} g\left(h^{2}-b^{2}\right)}{B_{\mathrm{o}} \mu_{\mathrm{o}} \ln \frac{r_{\mathrm{e}}}{r_{\mathrm{w}}}}
$$

where $q_{\mathrm{c}}$ is surface critical production, $B_{\mathrm{o}}$ is volume factor of oil, and $b$ is the thickness of perforation.

Considering the well skin factor, finally we obtain the critical well production before the water breakthrough.

$$
q_{\mathrm{c}}=\frac{\pi k \Delta \rho_{\mathrm{g} o} g\left(h^{2}-b^{2}\right)}{B_{\mathrm{o}} \mu_{\mathrm{o}}\left(\ln \frac{r_{\mathrm{e}}}{r_{\mathrm{w}}}+s\right)}
$$

where $s$ is the skin factor.

\subsection{Critical Production Calculation after Water Breakthrough}

After the breakthrough, both the oil phase and the water phase flow into the wellbore, Equation (11) is not applicable to calculate the production, but the phase production can be obtained with the same method.

For oil phase

$$
q_{\mathrm{oc}}=\frac{\pi k k_{\mathrm{ro}} \Delta \rho_{\mathrm{go}} g\left(h^{2}-b^{2}\right)}{B_{\mathrm{o}} \mu_{\mathrm{o}}\left(\ln \frac{r_{\mathrm{e}}}{r_{\mathrm{w}}}+s\right)}
$$

For water phase

$$
q_{\mathrm{ow}}=\frac{\pi k k_{\mathrm{rw}} \Delta \rho_{\mathrm{go}} g\left(h^{2}-b^{2}\right)}{B_{\mathrm{w}} \mu_{\mathrm{w}}\left(\ln \frac{r_{\mathrm{e}}}{r_{\mathrm{w}}}+s\right)}
$$

where $q_{\mathrm{oc}}$ is the critical production of oil phase, $k_{\mathrm{ro}}$ is the relative permeability of 
oil phase, $q_{\mathrm{ow}}$ is the critical production of water phase, $k_{\mathrm{rw}}$ is the relative permeability of water phase, $B_{\mathrm{w}}$ is volume factor of water, and $\mu_{\mathrm{w}}$ is viscosity of water.

Well critical production calculation after the water breakthrough is calculated by combining Equations (12) and (13).

$$
q_{\mathrm{c}}=q_{\mathrm{oc}}+q_{\mathrm{wc}}=\frac{\pi k k_{\mathrm{ro}} \Delta \rho_{\mathrm{go}} g\left(h^{2}-b^{2}\right)}{B_{\mathrm{o}} \mu_{\mathrm{o}}\left(\ln \frac{r_{\mathrm{e}}}{r_{\mathrm{w}}}+s\right)}+\frac{\pi k k_{\mathrm{rw}} \Delta \rho_{\mathrm{go}} g\left(h^{2}-b^{2}\right)}{B_{\mathrm{w}} \mu_{\mathrm{w}}\left(\ln \frac{r_{\mathrm{e}}}{r_{\mathrm{w}}}+s\right)}
$$

Water cut is an important evaluation index after the water breakthrough. Equation (14) is used as a function of water cut for filed application. Relative permeability curve is the function of water saturation, and is inducted to calculate the relation between critical and water cut. The specific steps are as follows. First the relationship between water saturation and water cut was stabilized by calculating water cut with relative permeability carve. Then the inverse method was used to calculate the water saturation with practical well water cut and relevant oil/water relative permeability was obtained. Finally the critical rate was calculated by introducing relative permeability to Equation (14).

\section{Critical Production of Horizontal Wells}

Calculation method of critical production for horizontal wells was studied by using 3D flow theory. A 3D flow field of horizontal wells in formation consists of two $2 \mathrm{D}$ flow regions (the inner region and outer region, as shown in Figure 2). Every $2 \mathrm{D}$ flow region is equivalent to a vertical well. In the inner region, cross section $\mathrm{A}$ is considered as a horizontal circle drainage area, where $R_{\mathrm{e}}$ is outer drainage radius, $P_{\mathrm{e}}$ is bounder pressure, $R_{\mathrm{p}}$ is equivalent well radius, and $P_{\mathrm{wf}}$ is bottom hole flowing pressure, as shown in Figure 3(a). In the outer region, cross section B is considered as a vertical drainage area, where $r_{\mathrm{w}}$ is wellbore radius, and $r_{\mathrm{e}}$ is inner drainage radius, as shown in Figure 3(b).

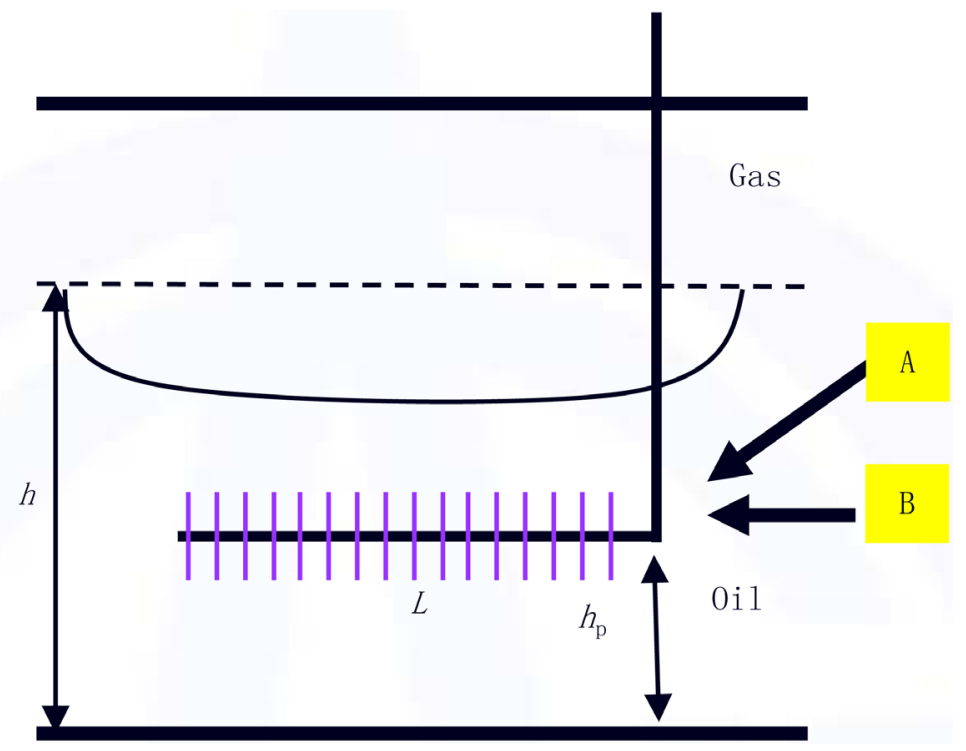

Figure 2. Diagram of horizontal well exploit reservoir with gas cap. 


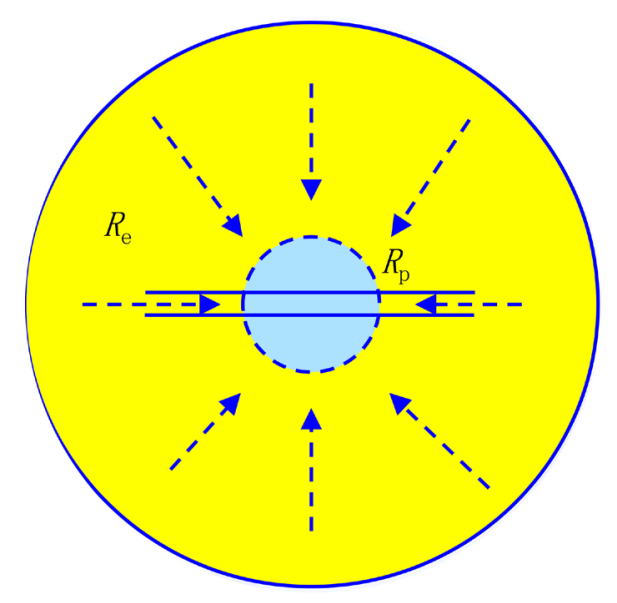

(a) Outer flow region

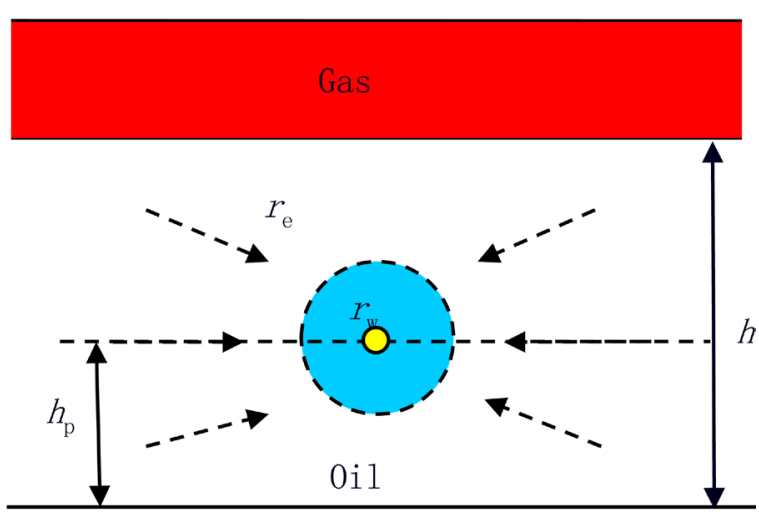

(b) Inner flow region

Figure 3. Classified flow region of horizontal well in formation.

\subsection{Critical Production Calculation before Water Breakthrough}

For the outer flow region, critical production of horizontal well can be obtained from Equation (10).

$$
q_{\mathrm{c} 1}=\frac{\pi k_{\mathrm{h}} \Delta \rho_{\mathrm{go}} g\left(h^{2}-h_{\mathrm{p}}^{2}\right)}{B_{\mathrm{o}} \mu_{\mathrm{o}}\left(\ln \frac{R_{\mathrm{e}}}{R_{\mathrm{p}}}+s\right)}
$$

where $R_{\mathrm{e}}=\sqrt{\frac{M}{\pi}}=\frac{a+\sqrt{a^{2}-\left(\frac{L}{2}\right)^{2}}}{2}$, and $R_{\mathrm{p}}=L / 4 . q_{\mathrm{cl}}$ is the critical production of outer flow region, $M$ is drainage area, $a$ is the long half axle of elliptical flow region, $L$ is the length of horizontal well, $k_{\mathrm{h}}$ is the horizontal permeability, $h_{\mathrm{p}}$ is the distance between the wellbore and the reservoir bottom, $R_{\mathrm{e}}$ is the drainage radius, and $R_{\mathrm{p}}$ is the equivalent well radius of circular drainage area.

For inner flow region, considering the well length as thickness, the production of horizontal well in vertical cross-section can be expressed with horizontal radial fluid flow method.

$$
q_{\mathrm{c} 2}=\frac{2 \pi k_{\mathrm{v}} L \Delta p}{B_{\mathrm{o}} \mu_{\mathrm{o}}\left(\ln \frac{r_{\mathrm{e}}}{r_{\mathrm{w}}}+s\right)}
$$

where $r_{\mathrm{e}}=h_{\mathrm{p}} \cdot q_{\mathrm{c} 2}$ is the critical production of inner flow region, $r_{\mathrm{e}}$ is the drainage radius of inner flow region, $k_{\mathrm{v}}$ is the vertical permeability, and $\Delta p$ is the pressure difference.

When the production of the outer region is the critical production, the pressure difference can be expressed as

$$
\Delta p=\frac{\Delta \rho_{\mathrm{go}} g\left(h^{2}-h_{\mathrm{p}}^{2}\right)}{2 h}
$$

Combining Equation (16) and (17), we can obtain 


$$
q_{\mathrm{c} 2}=\frac{\pi k_{\mathrm{v}} L \Delta \rho_{\mathrm{go}} g\left(h^{2}-h_{\mathrm{p}}^{2}\right)}{B_{\mathrm{o}} \mu_{\mathrm{o}} h\left(\ln \frac{r_{\mathrm{e}}}{r_{\mathrm{w}}}+s\right)}
$$

And the critical production of horizontal wells before water breakthrough can be expressed as

$$
q_{\mathrm{c}}=q_{\mathrm{c} 1}+q_{\mathrm{c} 2}=\frac{\pi k_{\mathrm{h}} \Delta \rho_{\mathrm{go}} g\left(h^{2}-h_{\mathrm{p}}^{2}\right)}{B_{\mathrm{o}} \mu_{\mathrm{o}}\left(\ln \frac{R_{\mathrm{e}}}{R_{\mathrm{p}}}+s\right)}+\frac{\pi k_{\mathrm{v}} L \Delta \rho_{\mathrm{go}} g\left(h^{2}-h_{\mathrm{p}}^{2}\right)}{B_{\mathrm{o}} \mu_{\mathrm{o}} h\left(\ln \frac{r_{\mathrm{e}}}{r_{\mathrm{w}}}+s\right)}
$$

\subsection{Critical Production Calculation after Water Breakthrough}

After water breakthrough, critical production of horizontal wells can be calculated using the same method as the directional wells.

Critical production of outer flow region is

$$
q_{\mathrm{c} 1}=\frac{\pi k_{\mathrm{h}} \Delta \rho_{\mathrm{g} 0} g\left(h^{2}-h_{\mathrm{p}}^{2}\right)}{\ln \frac{R_{\mathrm{e}}}{R_{\mathrm{p}}}+s}\left(\frac{k_{\mathrm{ro}}}{B_{\mathrm{o}} \mu_{\mathrm{o}}}+\frac{k_{\mathrm{rw}}}{B_{\mathrm{w}} \mu_{\mathrm{w}}}\right)
$$

Critical production of inner flow region is

$$
q_{\mathrm{c} 2}=\frac{\pi k_{\mathrm{v}} L \Delta \rho_{\mathrm{go}} g\left(h^{2}-h_{\mathrm{p}}^{2}\right)}{h\left(\ln \frac{r_{\mathrm{e}}}{r_{\mathrm{w}}}+s\right)}\left(\frac{k_{\mathrm{ro}}}{B_{\mathrm{o}} \mu_{\mathrm{o}}}+\frac{k_{\mathrm{rw}}}{B_{\mathrm{w}} \mu_{\mathrm{w}}}\right)
$$

Critical production is

$$
q_{\mathrm{c}}=\pi k_{\mathrm{h}} \Delta \rho_{\mathrm{g} 0} g\left(h^{2}-h_{\mathrm{p}}{ }^{2}\right)\left[\frac{k_{\mathrm{h}}}{\ln \frac{R_{\mathrm{e}}}{R_{\mathrm{p}}}+s}+\frac{k_{\mathrm{v}} L}{h\left(\ln \frac{r_{\mathrm{e}}}{r_{\mathrm{w}}}+s\right)}\right]\left(\frac{k_{\mathrm{ro}}}{B_{\mathrm{o}} \mu_{\mathrm{o}}}+\frac{k_{\mathrm{rw}}}{B_{\mathrm{w}} \mu_{\mathrm{w}}}\right)
$$

The relationship between critical production and water cut can be established by the same method of directional wells.

\section{Factor Analysis}

Factor analysis was carried out using data from Bohai oilfield. The layer geological and fluid parameters are shown as Table 1.

As shown in Figure 4, for horizontal wells, when the water cut is the same, the critical production increases with the increment of the horizontal permeability and the ratio of vertical permeability to horizontal permeability. This is because the better the reservoir property is, the greater the production capacity is and the better the stability of gas cone is. Directional wells also have similar laws.

As shown in Figure 5, for horizontal wells, when the water cut is the same, critical production increases with the increment of the reservoir thickness and the horizontal well length. This is because the thicker the reservoir is, the farther the oil-gas interface is from the perforation section or the horizontal section, and 
Table 1. Geological and fluid parameters of reservoir.

\begin{tabular}{|c|c|c|c|c|c|c|c|c|}
\hline Parameters & Permeability/mD & $\begin{array}{c}\text { Net } \\
\text { thickness/ } \\
\text { m }\end{array}$ & $\begin{array}{c}\text { Oil } \\
\text { viscosity/ } \\
(\mathrm{mPa} \cdot \mathrm{s})\end{array}$ & $\begin{array}{c}\text { Water } \\
\text { viscosity/(mPa.s) }\end{array}$ & $\begin{array}{c}\text { Oil } \\
\text { density } /\left(\mathrm{g} \cdot \mathrm{cm}^{-3}\right)\end{array}$ & $\begin{array}{c}\text { Oil volume } \\
\text { factor } /\left(\mathrm{m} \cdot \mathrm{m}^{-3}\right)\end{array}$ & $\begin{array}{l}\text { Water volume } \\
\text { factor } /\left(\mathrm{m} \cdot \mathrm{m}^{-3}\right)\end{array}$ & $\begin{array}{c}\text { Horizontal } \\
\text { well length } / \mathrm{m}\end{array}$ \\
\hline Values & 1000 & 10 & 3 & 0.5 & 850 & 1.14 & 1.01 & 400 \\
\hline
\end{tabular}

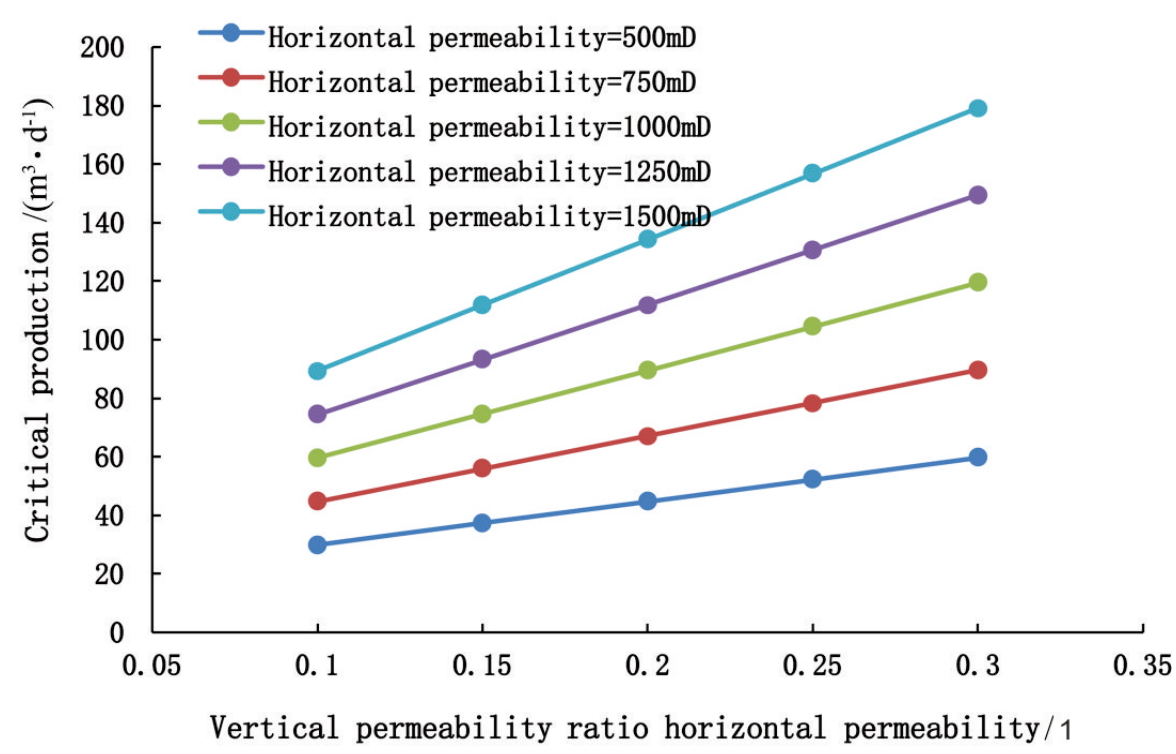

Figure 4. Critical production curve to different permeability.

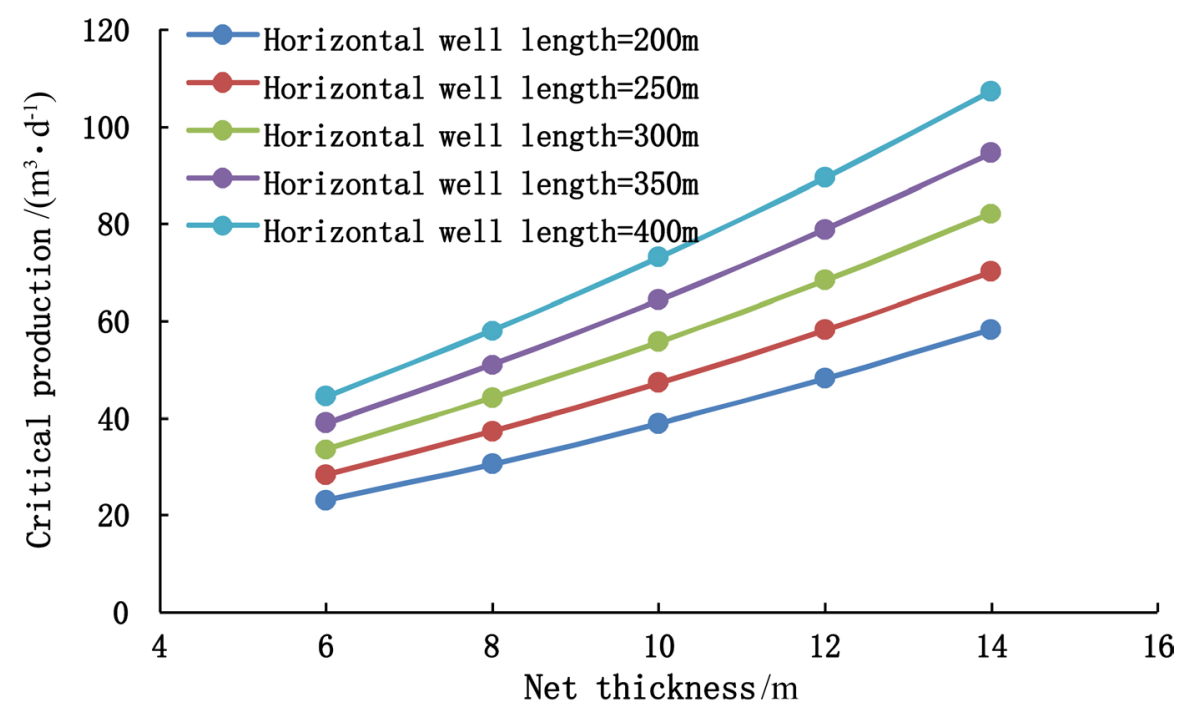

Figure 5. Critical production curve to different reservoir thickness and well length.

the less likely it is for the gas channeling to occur. For horizontal wells, the longer the horizontal section is, the more stable the gas cone is, and the less likely it is for the gas channeling to occur. Directional wells also have similar laws in net thickness.

Taking horizontal wells for example, critical productions of different oil viscosity on different water cut stages were plotted as shown Figure 6. When the produce pressure difference is the same, and the oil viscosity is less than 10 $\mathrm{mPa} \cdot \mathrm{s}$; the critical production decreases firstly and then increases with the in- 
crement of water cut. If the critical production before breakthrough is set to well work system, gas channeling will happen. So the well production should be limited after the water breakthrough to avoid gas channeling. When the oil viscosity is larger than $10 \mathrm{mPa} \cdot \mathrm{s}$, the critical production increases with the increment of water cut. Raising liquid production of well properly can be implemented when the water cut is high. Directional wells also have similar laws.

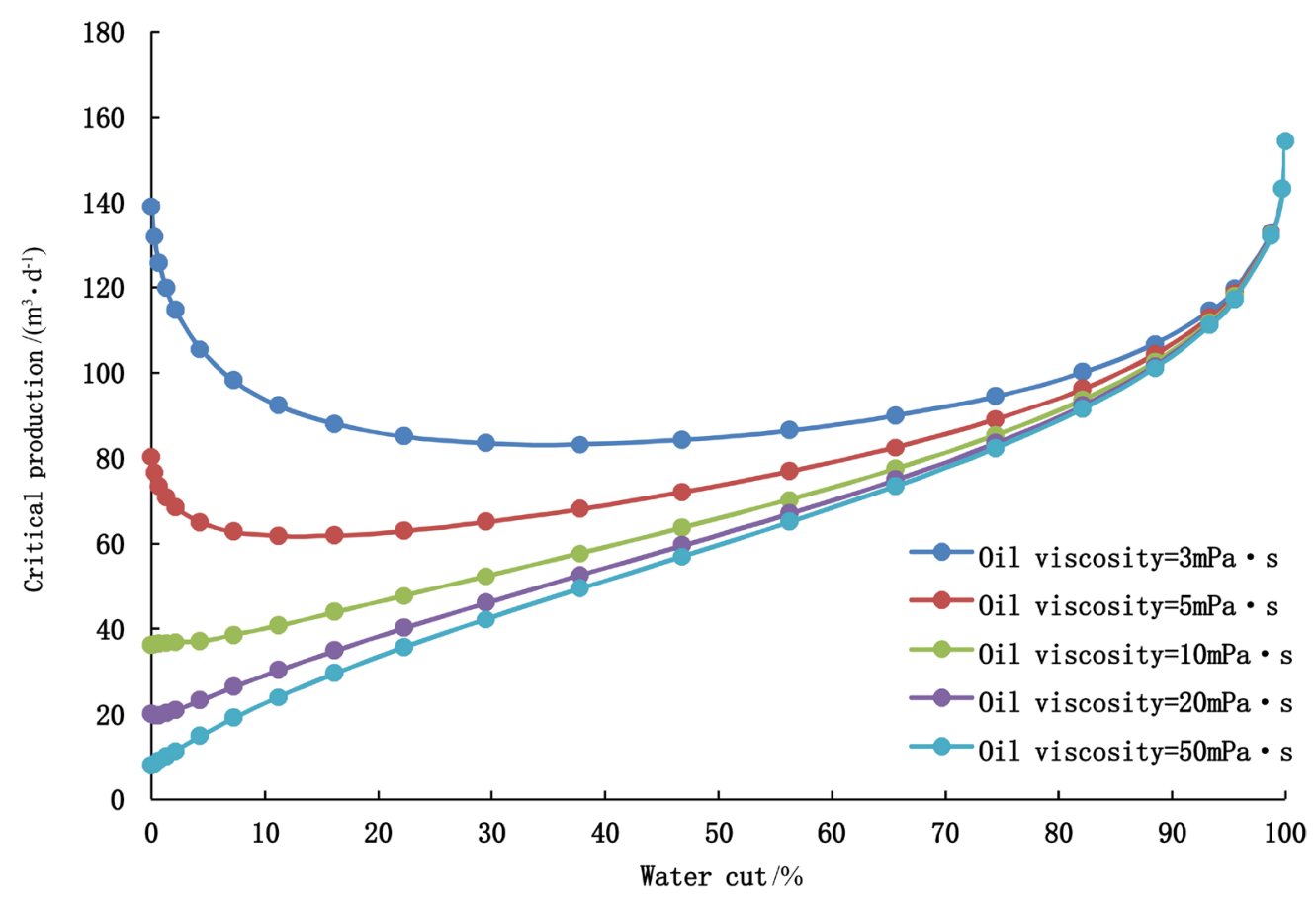

Figure 6. Critical production curve to different oil viscosity.

\section{Example Applications}

BZ oilfield is a complex fault-block oil field with gas cap on Bohai bay yellow river estuary sag. The reliability of the method was illustrated by an example of a well. The critical production of a production well was calculated by using Equations (19) and (22). The critical production before water breakthrough was 139 $\mathrm{m}^{3} / \mathrm{d}$. But when the water cut is $20 \%$, the critical production is $92 \mathrm{~m}^{3} / \mathrm{d}$. Then the working system of the well was adjusted according to the calculated results. The daily fluid production was limited from $110 \mathrm{~m}^{3} / \mathrm{d}$ to $80 \mathrm{~m}^{3} / \mathrm{d}$. Production proration of the other wells was optimized using the study results. The steam oil ratio of oilfield goes down and oil production goes steadily after optimization as shown in Figure 7.

This method is also applied in other wells. For the wells that are not degassed and whose production is lower than the critical production, raising the pump frequency can be used to increase oil production. For the wells that have been degassed and whose production exceeds the critical production rate, reducing the pump frequency or reducing the choke size can be used to decrease the liquid rate and control the gas channeling. Accordingly, the working system of 18 wells near gas cap in BZ oilfield was optimized, and the measurement was estab- 
lished with "single well customization". Five wells were treated with increasing the pump frequency, and six wells were treated with decreasing the chock size or pump frequency. The daily oil of 11 wells was increased by $94 \mathrm{~m}^{3} / \mathrm{d}$ by working system optimization (Table 2).

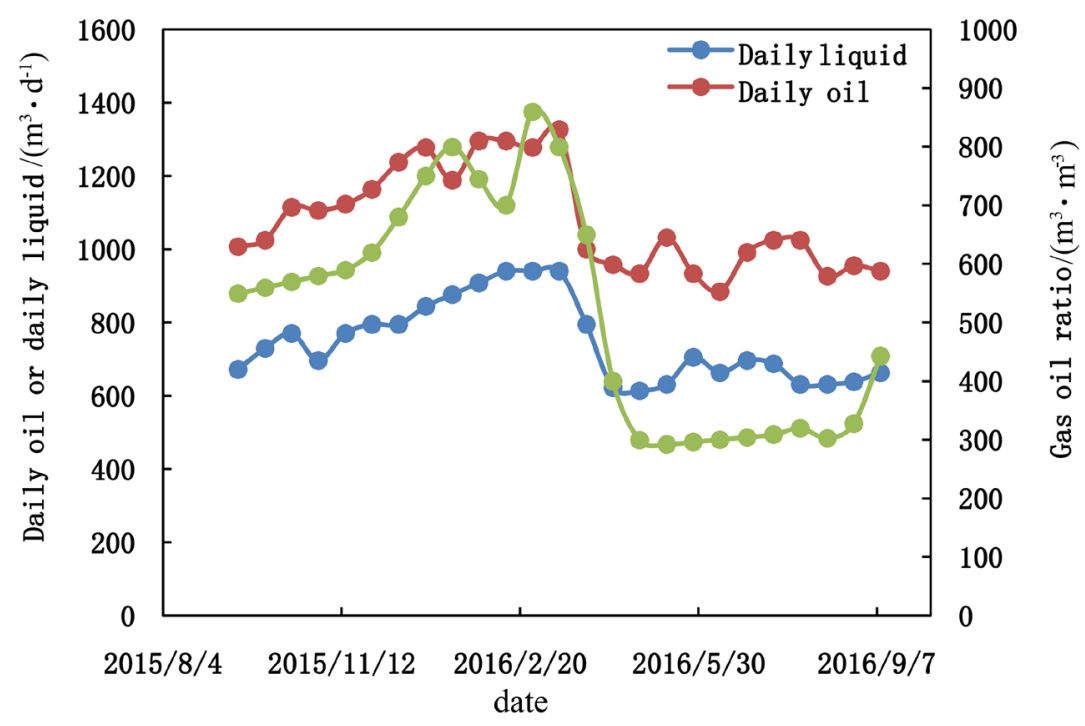

Figure 7. Production history curve of oilfield.

Table 2. Effect of 11 wells working system optimization in gas cap reservoir of BZ oilfield.

\begin{tabular}{|c|c|c|c|c|c|c|c|c|c|c|c|c|}
\hline \multirow[b]{2}{*}{$\begin{array}{l}\text { Well } \\
\text { No. }\end{array}$} & \multirow[b]{2}{*}{$\begin{array}{c}\text { Oil } \\
\text { Viscosity } \\
/ \mathrm{mPa} \cdot \mathrm{s}\end{array}$} & \multicolumn{5}{|c|}{ Before optimization } & \multirow[b]{2}{*}{ Measure } & \multicolumn{5}{|c|}{ After optimization } \\
\hline & & $\begin{array}{l}\text { Liquid } \\
/\left(\mathrm{m}^{3} \cdot \mathrm{d}^{-1}\right)\end{array}$ & $\begin{array}{c}\text { Oil } \\
/\left(\mathrm{m}^{3} \cdot \mathrm{d}^{-1}\right)\end{array}$ & $\begin{array}{l}\text { Water } \\
\text { cut } / \%\end{array}$ & $\begin{array}{c}\text { GOR } \\
/\left(\mathrm{m}^{3} \cdot \mathrm{m}^{-3}\right)\end{array}$ & $\begin{array}{c}\text { Calculated critical } \\
\text { production } \\
/\left(\mathrm{m}^{3} \cdot \mathrm{d}^{-1}\right)\end{array}$ & & $\begin{array}{l}\text { Liquid } \\
/\left(\mathrm{m}^{3} \cdot \mathrm{d}^{-1}\right)\end{array}$ & $\begin{array}{c}\text { Oil } \\
/\left(\mathrm{m}^{3} \cdot \mathrm{d}^{-1}\right)\end{array}$ & $\begin{array}{c}\text { Water cut } \\
/ \%\end{array}$ & $\begin{array}{c}\text { GOR } \\
/\left(\mathrm{m}^{3} \cdot \mathrm{m}^{-3}\right)\end{array}$ & $\begin{array}{l}\text { Oil increment } \\
/\left(\mathrm{m}^{3} \cdot \mathrm{m}^{-3}\right)\end{array}$ \\
\hline $\mathrm{A} 01 \mathrm{~h}$ & 10 & 80 & 23 & 71.3 & 38 & 116 & \multirow{6}{*}{$\begin{array}{l}\text { Pump } \\
\text { frequency } \\
\text { increasing }\end{array}$} & 115 & 33 & 71.4 & 42 & 10 \\
\hline A10h & 3 & 100 & 98 & 2 & 61 & 160 & & 157 & 155 & 1.3 & 63 & 57 \\
\hline A13h & 5 & 61 & 29 & 52.5 & 50 & 93 & & 90 & 41 & 54.4 & 53 & 12 \\
\hline A37h & 10 & 71 & 16 & 77.5 & 46 & 120 & & 120 & 25 & 79.2 & 47 & 9 \\
\hline $\mathrm{F} 22 \mathrm{~h}$ & 3 & 73 & 45 & 38.4 & 65 & 105 & & 105 & 64 & 39 & 75 & 19 \\
\hline $\mathrm{A} 02 \mathrm{~h}$ & 5 & 110 & 108 & 1.8 & 167 & 100 & & 100 & 99 & 1 & 122 & -9 \\
\hline D02h & 10 & 58 & 30 & 48.3 & 90 & 45 & \multirow{3}{*}{$\begin{array}{c}\text { Pump } \\
\text { frequency } \\
\text { decreasing }\end{array}$} & 41 & 25 & 39 & 61 & -5 \\
\hline A19h & 1.5 & 166 & 98 & 41 & 166 & 145 & & 140 & 103 & 26.4 & 108 & 5 \\
\hline A29h & 3 & 122 & 20 & 83.7 & 187 & 90 & & 90 & 23 & 74.4 & 120 & 3 \\
\hline $\mathrm{A} 33 \mathrm{~h}$ & 3 & 100 & 71 & 29 & 221 & 80 & \multirow{3}{*}{$\begin{array}{c}\text { Shrink the } \\
\text { nozzle }\end{array}$} & 80 & 66 & 17.5 & 155 & -5 \\
\hline $\mathrm{F} 32 \mathrm{~h}$ & 1.5 & 167 & 101 & 39.5 & 149 & 140 & & 140 & 99 & 29.3 & 117 & -2 \\
\hline & & & & & & Summation & & & & & & 94 \\
\hline
\end{tabular}

\section{Conclusions}

1) New critical production calculation method of directional wells in a water flooding reservoir with gas cap was established according to fluid hydraulics equilibrium, radial fluid flow theory and oil/water relative permeability relationship). The critical production after water breakthrough can be obtained by the method. 
2) New critical production calculation method of horizontal wells was set up using 3D flow field decomposition theory of horizontal wells.

3) Oil viscosity affects the relationship between critical production and water cut. When the oil viscosity is low, the critical production decreases firstly and then increases with the increment of the water cut. Well working system should be adjusted to avoid gas channeling. And when the oil viscosity is high, the critical production increases with the increment of the water cut. Liquid production of wells can be raised properly.

\section{Conflicts of Interest}

The authors declare no conflicts of interest regarding the publication of this paper.

\section{References}

[1] Muskat, M. and Wycokoff, R.D. (1935) An Approximate Theory of Water-Coning in Oil Production. Transactions of the AIME, 114, 144-163. https://doi.org/10.2118/935144-G

[2] Mayer, H.I. and Garder, A.O. (1954) Mechanics of Two Immiscible Fluids in Porous Media. Journal of Applied Physics, 25, 1400-1406. https://doi.org/10.1063/1.1721576

[3] Schols, R.S. (1972) An Empirical Formula for the Critical Oil Production Rate. Erdoel-Erdgas, 88, 6-11.

[4] Wheatley, M.J. (1985) An Approximate Theory of Oil/Water Coning. SPE Annual Technical Conference and Exhibition, Las Vegas, 22-26 September 1985, SPE-14210. https://doi.org/10.2118/14210-MS

[5] Chaperon, I. (1986) Theoretical Study of Coning toward Horizontal and Vertical Well in Anisotropic Formations: Subcritical and Critical Rates. SPE Annual Technical Conference and Exhibition, New Orleans, 5-8 October 1986, SPE-15377.

[6] Giger, F.M. (1989) Analytic Two-Dimension Models of Water Cresting before Breakthrough for Horizontal Wells. SPE Reservoir Evaluation \& Engineering, 4, 409-416. https://doi.org/10.2118/15378-PA

[7] Joshi, S.D. (1991) Horizontal Well Technology. PennWell Publishing Company, Tulsa, 59-105.

[8] B., Guo and Lee, R.L. (1992) Determination of the Maximum Water-free Production Rate of a Horizontal Well with Water-Oil-Interface Cresting. SPE Rocky Mountain Regional Meeting, Casper, 18-21 May 1992, SPE-24324.

[9] Fan, Z.F. and Lin, Z.F. (1994) A Study of Critical Rate of a Horizontal Well in a Reservoir with Bottom-Water Drive. Petroleum Exploration and Development, 21, 65-70.

[10] Dou, H.E. (1994) Calculation of Critical Flow Rate for Horizontal Well in Bottom-Water Oil Reservoir. Oil Drilling \& Production Technology, 21, 70-75.

[11] Zhou, D.Y., Jiang, T.W., Zhao, J.Z., et al. (1995) The Uncertainty and Prediction of Critical Output of Horizontal Wells in Bottom Water Reservoir. Drilling \& Production Technology, 28, 33-36.

[12] Li, C.L., Yang, B.X. and Cheng, L.S. (2004) A Method to Determine the Optimum Perforation Place and Height in a Vertical Well of Gas-Water Coning Reservoir. China Offshore Oil and Gas, 16, 105-106. 
[13] Rao, Z., Wu, F. and Li, X.P. (2006) The Method of Ascertaining the Horizontal Well's Reasonable Position in Gas-Cap Reservoir. Journal of Southwest Petroleum Institute, 28, 7+42-44.

[14] Lv, A.M. and Yao, J. (2007) Study on Optimal Vertical Position of Horizontal Well in Gas-Cap Reservoir. Oil Drilling \& Production Technology, 29, 98-99.

[15] Wang, D.L., Ling, J.J., Zheng, S.J., et al. (2008) Study on Optimum Vertical Location of Horizontal Wells in Reservoir with Bottom Water and Gas Cap. Fault-Block Oil and Gas Field, 15, 76-79.

[16] Yao, K., Chen, S.Y., Jiang, H.Q., et al. (2009) Research and Application of Critical Productivity in Water-Driving Development Horizontal Well Reservoirs. Petroleum Geology and Recovery efficiency, 16, 77-80.

[17] Zhou, K., Tang, H., Lv, D.L., et al. (2010) Optimum Perforated Position for Gas Cap and Bottom Water Reservoir. Well Testing, 19, 8-10.

[18] Chen, Y.Q. (2010) New Methods to Predict Critical Production Rates in Horizontal Wells with Water and Gas Coning. China Offshore Oil and Gas, 22, 22-26.

[19] Tu, B., Han, J. and Sun, J. (2014) A Calculation Method of Critical Production for Oil Wells in Thick Reservoirs with Bottom Water. Petroleum Drilling Techniques, 42, 107-110.

[20] Yuan, L., Li, X.P. and Liu, P.P. (2015) New Method for Determining Critical Rate of Horizontal Well in Gas Cap and Bottom Water Reservoirs. Lithologic Reservoirs, 27, 122-126.

[21] Yuan, L., Li, X.P. and Yan, Y.C. (2015) New Method for Determination of Horizontal Well Critical Output in Bottom-Water Reservoir. Natural Gas and Oil, 33, 65-68.

[22] Zhang, Y., Tang, L.D., Xu, Y.D., et al. (2017) Research on Critical Production of Heavy Oil Reservoir with Bottom Water. Natural Gas and Oil, 35, 72-75. 